invadens under anaerobic and aerobic conditions. Antimicrob Agents Chemother. 1976;9:696-700.

6 Muller M, Meingassner JG, Miller WA, Ledger WJ. Three metronidazole-resistant strains of Trichomonas vaginalis from the United States. Am $₹$ Obstet Gynecol 1980;138:808-12.

7 Smith RF, DiDomenico A. Measuring the in vitro susceptibility of Trichomonas vaginalis to metronidazole. Sex trasm Dis 1980;7:120-4.

Accepted for publication 18 December 1992.

\section{STD Diagnostics Initiative}

Sexually transmitted diseases (STDs) are an important cause of morbidity and mortality worldwide. In many developing countries the incidence of treatable STDs continues to rise and in some countries has reached epidemic proportions. Both genital ulcer disease and non-ulcerative STDs are associated with a three- to five-fold increased risk of human immunodeficiency virus (HIV) transmission.

In light of the prevalence of STDs in many countries, work is ongoing to develop or strengthen STD control programs in many parts of the world. An integral part of this effort is the identification, development, and introduction of affordable diagnostic tests appropriate for use in resource-limited health care settings, particularly those serving women of reproductive age in whom most infections are asymptomatic. To adequately meet global need, these diagnostics must be:

- Inexpensive - cost to the provider of less than US $\$ 1.00$ per patient

- Simple-minimal training and simple or no equipment required

- Rapid-results available before patient leaves clinic

- Convenient-specimens simple to collect, socioculturally acceptable, minimal preparation required

- Stable-reagents have long shelf life, no refrigeration required

- Functional-packaged simply, low cost

- Accurate-appropriately sensitive and specific, taking into account the potential morbidity and cost associated with undetected infection and the cost of treatment

To stimulate and sustain the development and/or adaptation of appropriate STD diagnostics, the STD Diagnostics Initiative was formed in November 1990. The goal of this multilateral Initiative is to facilitate the development and distribution of affordable diagnostic tests appropriate for use in resource-limited settings and to help integrate these tests into STD prevention and control programs. In working toward this goal, the Initiative interacts with researchers, manufacturers, STD and maternal and child health program managers, clinicians, laboratory workers, and representatives of international health and donor agencies. At present, the Initiative's interests are focussed on:

- Chlamydial and gonococcal diagnostic tests or indicators, primarily for women, which would reduce the incidence of reproductive tract complications of infection and the expense of treatment.
Simple diagnostic tests or simplified test procedures for STD pathogens (i.e. Treponema pallidum, Haemophilus ducreyi, HSV) which are associated with increased risk of HIV transmission.

- Simple indicators which can be effectively used with syndromic algorithms.

Serological tests for $T$ pallidum, HSV-2, and $H$ ducreyi for epidemiological surveillance and evaluation in STD/AIDS control programs.

For more information about the Initiative, please contact the Secretariat for the STD Diagnostics Initiative, Program for Appropriate Technology in Health (PATH), 4 . Nickerson Street, Seattle, Washington 98109-1699, U.S.A.

SETH BERKLEY Chairman, Steering Committee, STD Diagnostics Initiative

Accepted for publication 4 February 1993.

\section{HIV disease in Africans of high social class}

The majority of research on AIDS in Africa has been performed in Government institutions, which tend to be used by the poorest members of society. Few studies have elicited the clinical presentations of $\mathrm{HV}$ disease in those who are affluent, or have described the epidemiological features in this group. ${ }^{12}$

Discharge data were collected retrospectively on all admissions who were HIV positive on a general medical ward at the Aga Khan Hospital (AKH), Nairobi, Kenya, between 1 September 1990 and 28 February 1991. HIV testing was performed on clinical grounds. Epidemiological data were obtained by KER interviewing 23 consecutive HIV positive patients attending an outpatient clinic, using a structured questionnaire.

There were 1041 medical admissions (666 men, 375 women) and $121(12 \%)$ cases $(116$ patients) were HIV positive ( $15 \%$ of men, $5 \%$ of women). The number of negative HIV results is unknown. The admissions comprised 98 men (mean age 36.5 years, range 22-52) and 18 women (mean age 30.4 years, range 17-55). HIV status was previously unknown in $74 \%$. The presenting diagnoses are shown in the table. Neuropsychiatric

Table 1 Medical diagnoses in HIV positive patients

\begin{tabular}{lcll}
\hline $\begin{array}{l}\text { Diagnosis } \\
\text { (\%) }\end{array}$ & $\begin{array}{l}\text { Male } \\
n=98\end{array}$ & $\begin{array}{l}\text { Female } \\
n=18\end{array}$ & $\begin{array}{l}\text { Total } \\
n=116\end{array}$ \\
\hline Pulmonary tuberculosis & 21 & 7 & $28(24)$ \\
Neuro-psychiatric disease & 14 & 2 & $16(14)$ \\
Herpes zoster & 7 & 2 & $9(8)$ \\
Gastroenteritis & 8 & 0 & $8(7)$ \\
Bacterial pneumonia & 8 & 1 & $9(8)$ \\
Malaria & 3 & 2 & $5(4)$ \\
Urinary tract infection & 5 & 0 & $5(4)$ \\
Pyrexia of unknown origin & 3 & 1 & $4(3)$ \\
Anaemia of unknown cause & 1 & 2 & $3(3)$ \\
Nephrotic syndrome & 1 & 1 & $2(2)$ \\
Salmonella typhi & 1 & 0 & $1(1)$ \\
Salmonella paratyphi & 1 & 0 & $1(1)$ \\
Histoplasmosis & 1 & 0 & $1(1)$ \\
Bubonic plague & 1 & 0 & $1(1)$ \\
Eczema & 1 & 0 & $1(1)$ \\
Perianal abscess & 1 & 0 & $1(1)$ \\
Oesophagitis & 1 & 0 & $1(1)$ \\
Hodgkin's disease & 1 & 0 & $1(1)$ \\
Unknown & 22 & 0 & $22(19)$ \\
\hline
\end{tabular}


problems included: acute schizophrenia (3), depression (2), neuropathy (2), dementia (2), seizure (1), cerebral abscess (1), attempted suicide (1), confusion (3) and coma (1). Death occurred in 13 patients from pulmonary tuberculosis (4) gastroenteritis (2) coma (2) Hodgkins lymphoma (1) histoplasmosis (1) Salmonella paratyphi (1) and unknown (2).

Epidemiological data were elicited on 13 men (mean age 38 years, range 30-52), and 10 women, mean age 32 years (range 19-51). Five women $(50 \%)$ and 10 men $(77 \%)$ were married. Two of the men each had two wives. Eight men and three women had previous genital ulcer disease $(48 \%)$ and three men had previous syphilis. Men were more likely to have a history of gonorrhoea than women (Fishers, $\mathrm{p}<0.01$ ), and to have more than 10 lifetime sexual partners (8) than women (0) $(p=0.0052)$. Three $(30 \%)$ women but no men had only one lifetime sexual partner. Seven men (54\%) admitted to prostitute use, and five (38\%) were circumcised. Scarification had occurred in six patients $(26 \%)$ and three women had received blood transfusions. The mean number of sexual partners in the preceding year was 2.9 for men (range $0-15$ ) and 0.6 for women (range $0-1)$. Four men had sexual intercourse in Europe or the USA in the preceding 5 years. Two of the six women with regular sexual partners had unprotected intercourse with an at-risk partner because they were too frightened to declare their HIV status. Only two of nine men who had had casual sex in the preceding year always used condoms.

We have shown that tuberculosis is common in the affluent as well as the poor ${ }^{3}$ who have HIV infection and that HIV disease is a significant problem in this private hospital. Although a higher percentage of infected patients $(19 \%)$, especially women $(17 \%)$, was found at a government hospital, ${ }^{4} \mathrm{HIV}$ testing at the AKH was only performed when indicated, therefore results are biased and the true incidence is likely to be higher.

One must be cautious in extrapolating epidemiological data to affluent Kenyans as a whole, in view of the small numbers. These preliminary data suggest the same risk factors as in the less affluent and that prostitute use is also a risk factor, despite the finding of a lower incidence of HIV infection in prostitutes of upper $(31 \%)$ compared with lower socio-economic strata (66\%). ${ }^{5}$ Despite awareness of their status, many patients continue to engage in unprotected sexual intercourse, suggesting new efforts to reduce HIV transmission in Africa must take into account cultural differences from the West. ${ }^{6}$

KER expresses her gratitude to the patients of the Aga Khan Hospital, Nairobi, and to Trent Regional Health Authority for study leave and assistance towards travel. KAREN E ROGSTAD IMTYAZ H AHMED-JUSHUF Department of Genitourinary Medicine, City Hospital, Hucknall Rd,
Nottingham, UK

MOHAMMED S ABDULLAH G TESFALEDET Department of Medicine Aga Khan Hospital, Nairobi, Kenya

Address correspondence to: Dr K E Rogstad

Air travel to Kenya was aided by a grant from Trent Regional Health Authority.

1 Allen S, Lindan C, Servfilira A, et al. Human Immunodeficiency virus infection in urban Rwanda. $¥ A M A$ 1991;266:1657-63.

2 Ryder RW, Mibandumba N, Hassig SE, et al. Heterosexual transmission of HIV-1 among employees and their spouses at two large businesses in Zaire. AIDS 1990;4:725-32.

3 Gilks CF, Brindle RI, Otiento LS. Extrapulmonary and disseminated tuberculosis in HIV-1 seropositive patients disseminated tuberculosis in HIV-1 seropositive patients presenting to the acut
AIDS $1990 ; 4: 981-5$.

4 Gilks C, Brindle RJ, Otieno LS. Life threatening bacteraemia in HIV-1 seropositive adults admitted to hospital in Nairobi, Kenya. Lancet 1990;336:545-8.

5 Kreiss JK, Koech D, Plummer FA, et al. AIDS virus infection in Nairobi prostitutes: spread of the epidemic to East Africa. N Engl 7 Med 1986;314:414-8.

6 Brokensha D. Social factors in the transmission and control of African AIDS. In: AIDS in Africa, the social and policy impact. Miller and Rockwell. 